\title{
Comparative study of sympathetic cardiovascular parameters in overweight, normal and underweight school children in southern Odisha basing on BMI criteria
}

\author{
Dr. Debasish Das ${ }^{1}$, Dr. Bipin Bihari Pradhan ${ }^{2}$, Dr. Minati Patnaik ${ }^{3}$ \\ 1Post graduate student, Department of physiology, M.K.C.G Medical college, Berhampur, Odisha. \\ 2Associate Prof, Department of physiology, M.K.C.G Medical college, Berhampur, Odisha. \\ 3Prof. and Head of the department, , Department of physiology, M.K.C.G Medical college, Berhampur, Odisha
}

\begin{abstract}
This study was undertaken to investigate and compare the sympathetic cardio vascular parameters in age matched overweight, underweight and normal weight school going boys in southern Odisha. 75 Boys between age group of 12-16 were subjected to study out of which 25 were overweight (BMI>25), next 25 were underweight $(B M I<18.5)$,rest 25 were control group having normal BMI. Cold pressure test and hand grip dynamometer test were performed and blood pressure was measured during and after the tests as measures of cardiovascular parameter. Baseline SBP and MAP were significantly higher in overweight boys \& lower in underweight boys. Maximum rise of SBP, DBP \& MAP during hand grip dynamometer test were significantly higher in overweight boys \& lower in underweight boys. Increase in SBP \& MAP from their basal value during cold pressure test were significantly lower in overweight boys \& higher in underweight boys. Thus it is concluded that both overweight \& underweight boys have derangement of sympathetic cardiovascular function. SBP-Systolic blood pressure, DBP-Diastolic blood pressure ,MAP- Mean arterial pressure
\end{abstract}

\section{Introduction}

Prevalence of childhood obesity and overweight is seen now in urban areas causing various cardiovascular and endocrine health hazards. Studies have shown the relation between the autonomic activity and obesity 1). Energy balance is largely affected by ANS activity of individuals (2). The use of BMI for the prediction of risk factor clustering among children \& adolescent has significant clinical utility (3). It has been documented that ANS is significantly compromised in malnourished children (4)(5). Our study is undertaken to investigate and compare the sympathetic cardiovascular parameters in age matched overweight, underweight \& normal weight school going boys in southern Odisha.

\section{Method}

This prospective study was conducted in the research lab of Dept. of physiology, M.K.C.G. medical college, Berhampur, Odisha, during the period from Nov.2012 to May 2013 after due approval from the Institutional Ethics Committee. Study included 75 boys between age group 12-16 were subjected to study out of which 25 were normal(BMI-18.5-25), 25 were overweight(BMI>25), rest 25 were underweight(BMI<18.5). Each child was informed about the procedures and informed verbal consent was obtained from their parents or teachers. Subjects with any disease or abnormality were excluded from study. Height in $\mathrm{cm}$ and weight in $\mathrm{kg}$ were measured by Stadiometer and Digital weighing scale respectively. BMI was calculated using Quetlet's index.

BMI =weight $/$ height $\left(\mathrm{kg} /\right.$ meter $\left.^{2}\right)$

Blood pressure were recorded by Clarity Med (PMS 320) cardiac monitor.

Baseline SBP, DBP were recorded. MAP were calculated.

Hand grip dynamometer test:

Subject was asked to grip the Med scale hand grip dynamometer with their dominant hand at $30 \%$ of maximal voluntary contraction for 3 minutes. Maximum SBP, DBP, \& MAP change in BP from basal value were noted down for each minute. Mean was calculated.

Cold pressure test:

Subject was asked to immerse his hand in cold water (temp 4-6.C) for 1min. Then remove his hand. BP measurement was made from other arm at $30 \mathrm{sec} \& 1 \mathrm{~min}$ interval. Maximum increase \& change of BP (SBP, DBP, and MBP) was determined. Mean was calculated. 


\section{Observation:}

Table-1 Anthropometric characteristics between control \& study groups

\begin{tabular}{|l|l|l|l|}
\hline Variable & Control & Overweight & Underweight \\
\hline Age $(\mathrm{yr})$ & $14.2 \pm 0.8$ & $14.6 \pm 1.2$ & $14 \pm 0.9$ \\
\hline Height $(\mathrm{cm})$ & $157.4 \pm 6.6$ & $161.4 \pm 10.1$ & $158.1 \pm 8.1$ \\
\hline Weight $(\mathrm{kg})$ & $52 \pm 4.2$ & $72.2 \pm 12.8$ & $42.4 \pm 5.1$ \\
\hline BMI & $21 \pm 1.5$ & $27.5 \pm 3.1$ & $16.9 \pm 1.1$ \\
\hline
\end{tabular}

Table-2 Comparison of basal blood pressure response in control \& study groups

\begin{tabular}{|l|l|l|l|l|}
\hline Variable & Control & Underweight & Overweight & P-value \\
\hline SBP(mmhg) & $104.5 \pm 6.7$ & $104 \pm 10.4$ & $115.8 \pm 9.7$ & $0.0011^{*}$ \\
\hline DBP(mmhg & $65.6 \pm 6.3$ & $63.8 \pm 9.3$ & $69.4 \pm 5.5$ & 0.151 \\
\hline MAP(mmhg) & $78.6 \pm 5.1$ & $77.2 \pm 8.9$ & $84.9 \pm 5.7$ & $0.011^{*}$ \\
\hline
\end{tabular}

TABLE-3_comparison of blood pressure response to hand grip dynamometer

test in control \& study group

\begin{tabular}{|l|l|l|l|l|}
\hline Variable(mmhg) & Control & Underweight & Overweight & P-value \\
\hline SBP MAX & $127.7 \pm 12.5$ & $124.5 \pm 12.5$ & $137.8 \pm 13$ & $0.033^{*}$ \\
\hline SBP DIF & $23.1 \pm 10.7$ & $20.5 \pm 14.9$ & $22 \pm 13.1$ & 0.816 \\
\hline DBP MAX & $78.8 \pm 10$ & $77.5 \pm 9.1$ & $88.3 \pm 14.9$ & $0.034^{*}$ \\
\hline DBP DIF & $13.2 \pm 10.8$ & $13.6 \pm 11.9$ & $18.9 \pm 12.1$ & 0.369 \\
\hline MAP MAX & $95.1 \pm 10$ & $93.1 \pm 9$ & $104.8 \pm 13.6$ & $0.019^{*}$ \\
\hline MAP DIF & $16.5 \pm 9.7$ & $15.9 \pm 10.9$ & $19.9 \pm 11.5$ & 0.594 \\
\hline
\end{tabular}

TABLE-4 Comparison of blood pressure response to cold pressure test in

control \& study groups

\begin{tabular}{|l|l|l|l|l|}
\hline Variable(mmhg) & Control & Underweight & Overweight & P-value \\
\hline SBP MAX & $122.1 \pm 8.8$ & $128.6 \pm 12.8$ & $127 \pm 14.2$ & 0.177 \\
\hline SBP DIF & $17.5 \pm 10.7$ & $24.6 \pm 14.6$ & $11.2 \pm 9.2$ & $0.022^{*}$ \\
\hline DBP MAX & $77.9 \pm 8.8$ & $80.2 \pm 9.4$ & $80.1 \pm 10.1$ & 0.678 \\
\hline DBP DIF & $12.2 \pm 10.2$ & $16.3 \pm 10.2$ & $10.7 \pm 6.8$ & 0.314 \\
\hline MAP MAX & $92.6 \pm 7$ & $96.3 \pm 8.7$ & $95.8 \pm 11.1$ & 0.348 \\
\hline MAP DIF & $14 \pm 8$ & $19.1 \pm 9.3$ & $10.9 \pm 7$ & $0.0461^{*}$ \\
\hline
\end{tabular}

SBP-Systolic Blood Pressure, DBP-Diastolic Blood Pressure, MAP-Mean Arterial pressure MAX-Maximum increase in BP during a test

DIF- Difference between maximum increase in BP during a test from its basal value.

*- Statistical significant.

Statistical analysis:

All data are expressed as means $\pm \mathrm{sd}$. Differences between underweight, overweight \& normal weight groups were tested using one way Anova. A two tailed p-value less than 0.05 was statistical significant.

\section{Result:}

Basal SBP, DBP \& MAP are lowest in underweight \& highest in overweight subjects . From this only SBP \& DBP are statistical significant. During the Hand grip dynamometer test maximum rise of SBP ,DBP \& MAP were statistical significant. Rise is highest in overweight \& lowest in underweight subjects. Difference between maximum rise of SBP, DBP \& MAP from their basal value did not show any statistical significance . During the Cold pressure test the maximum rise of SBP, DBP \& MAP did not show any statistical significance. Difference of SBP, DBP \& MAP were lowest in overweight and highest in underweight subjects. From this only SBP \& MAP are statistical significant.

\section{Discussion:}

In overweight children initially sympathetic stimulation occur to reduce body weight (catabolic effect). That causes an increase in vasomotor tone \& cardiac output. So the final result is increase in basal SBP, DBP \& 
MAP in overweight children(6). But beyond equilibrium, sympathetic nervous system cannot act to reduce body weight. This causes sympathetic insufficiency in chronic overweight children which makes them prehypertensive. This is shown by these tests. Cold pressure test is an indicator of vasoconstrictor tone. The lesser increase in SBP, DBP \& MAP during cold pressure test from its basal value in overweight boys in compare to control group suggest sympathetic insufficiency(7). Sympathetic insufficiency leads to inadequate sympathetic cholinergic vasodilatation in contracting muscles resulting in significant increase in maximum SBP, DBP \& MAP during Hand grip dynamometer test (8). But in underweight boys sympathetic system is not sufficiently stimulated.

\section{Conclusion:}

Our results indicate sympathetic insufficiency in overweight children. Data for underweight children is not so contrast. So this study establishes the correlation of ANS (sympathetic activity), body weight regulation (energy balance) \& cardiovascular function.

\section{Reference}

[1]. Venkatnaraya KM, Campagna AF, Imperatore G. Type 2 diabetes in children : a problem lurking from india ? Indian Pediatr 2001; 38: 17

[2]. Bray GA. Autonomic and endocrine factors in the regulation of energy balance. Fed Proc. 1986 ; 45[5]:1404-1410

[3]. Katzmarzyk PT, Srinibash SR, Chen W, Malina RM, Bouchard C, and waist hip ratio as diagnostic tests for fatness in adolescents. Int J Obese 2004; doi:10.1038/sj.ijo.0802867, URL: www.nature.com.last accessed 3 Jan 2005.

[4]. Bedi M, Babbar R, Chakrabarty AS, Sachdev HP. Comparative study of autonomic nervous system activity in malnourished and normal children in India. Inn Trop Paediatr 1999;19: 185- 189.

[5]. Heinrich WL. Autonomic insufficiency. Arch Intern Med 1982; 142: 339-344.

[6]. Sorof J, Daniels S. Obesity hypertension in children. A problem of epidemic proportions. Hypertension 2005; 45: 1159-1164.

[7]. De Simone G, Mancini M, Turko S, Marotta I, Gaeta I, Lannuzzi R, Ferrara LA, Mancini M. Cardiovascular response to the cold test in obese subjects. Effect of a hypo caloric, normal sodium diet. Minerva endocrinol. 1990 Oct-Dec; 15(4): $231-233$.

[8]. Leary AC, Donnan PT, MacDonald TM, Murphy MB. The influence of physical activity on the variability of ambulatory blood pressue. Am J Hypertens. 2003; 13: 1067-73.

[9]. Ravisankar P, Madanmohan, Kaviraja U, and E. Sankaranarayanan Prakash. Correlation between body mass index and blood pressure indices, handgrip strength and handgrip endurance overweight adolescents. Indian J Physiol Pharmacol 2005; 49(4): 455461 .

[10]. Nageswari KR, Sharma R, Kohli DR. Assessment of respiratory and sympathetic cardiovascular parameters in obese school children. Indian J Physiol Pharmacol 2007;51(3):235-243. 